\title{
Screening and Extracting Mycocin Secreted by Yeast Isolated from Koumiss and Their Antibacterial Effect
}

\author{
Yujie Chen ${ }^{1}$, Chen Aorigele ${ }^{1, *}$, Chunjie Wang ${ }^{2}$, Huasai Simujide ${ }^{1}$, Siqin Yang $^{1}$ \\ ${ }^{1}$ College of Animal Science, Inner Mongolia Agricultural University, Hohhot, China \\ ${ }^{2}$ College of Veterinary Medicine, Inner Mongolia Agricultural University, Hohhot, China \\ *Corresponding author: aori6009@163.com
}

Received January 01, 2015; Revised January 21, 2015; Accepted January 26, 2015

\begin{abstract}
Koumiss is a common fermented mare's milk with beneficial therapeutic effects on cardiovascular disease, tuberculosis, and diarrhea. The mare's milk is fermented by lactic acid bacteria (LAB) and yeasts. Although information about LAB from Koumiss is comprehensive, there is limited knowledge about yeasts from Koumiss and their effects. The purpose of this study was to screen and extract mycocin secreted by yeast isolated from Koumiss and test their antibacterial effect against pathogenic Escherichia coli, The yeasts from Koumiss were isolated and those producing mycocin were screened by the Oxford cup method. Crude extracts of mycocin were then extracted by ethyl acetate, and temperature stabilities of them were investigated. The crude extracts of mycocin were tested against pathogenic E. coli and compared both in vivo and in vitro. Three Saccharomyces cerevisiae, and two Kluyveromyces marxianus were isolated from Koumiss in Inner Mongolia. All these yeasts produced mycocin. The two crude extracts of mycocin secreted by $K$. marxianus were active and stable at temperatures between $25^{\circ} \mathrm{C}$ and $45^{\circ} \mathrm{C}$. They had better antibacterial effect in vitro and in vivo and were shown to be effective in preventing $E$. coli disease in mice. It may be possible to use crude extracts of mycocin secreted by yeast isolated from Koumiss to inhibit the growth of $E$. coli.
\end{abstract}

Keywords: Koumiss, yeast, escherichia coli, mycocin

Cite This Article: Yujie Chen, Chen Aorigele, Chunjie Wang, Huasai Simujide, and Siqin Yang, "Screening and Extracting Mycocin Secreted by Yeast Isolated from Koumiss and Their Antibacterial Effect." Journal of Food and Nutrition Research, vol. 3, no. 1 (2015): 52-56. doi: 10.12691/jfnr-3-1-9.

\section{Introduction}

Fermentation is an ancient method to preserve foods, which not only extends their shelf life, but also enhances their texture and aroma [1,2,3]. Koumiss, a beverage fermented from mare's milk, is popular in some regions, such as Mongolia, Kazakhstan, Turkey, and regions of Asia and Europe [4]. To produce Koumiss, the mare's milk is heated at $90^{\circ} \mathrm{C}$ for 5 to $10 \mathrm{~min}$, then cooled to 26 to $28^{\circ} \mathrm{C}$ prior to inoculating 10 to $30 \%$ bacteria, and subsequently incubated 2 or 3 days [5]. LAB and yeasts are the main microorganisms from Koumiss, where LAB is well known, while there is little information on the yeasts present. However, it has been reported that the yeasts from Koumiss inhibit the growth of E. coli in vitro [6]. Other reported that killer toxins, organic acids, antibiotic factors, volatile acids, hydrogen peroxide, and various other substrates were secreted by yeasts from fermented foods and beverages [7]. Yeast killer toxins are proteinaceous compounds that are active against members of the same species or related species. Yeast killer toxins are referred to as mycocin and the killer strains mycogenic in order to emphasize the general nature of the antagonistic interactions [8]. The abuse of antibiotics induced the multiresistance and increased virulence in some pathogenic E. coli. Therefore, it is urgent to search for new and natural alternative antibacterial substance to treat or prevent $E$. coli infections, one of those could be the mycocin produced by the yeast isolated from Koumiss.

The purpose of this study was to screen and extract mycocin secreted by yeast isolated from Koumiss and test their antibacterial effect against $E$. coli, in vivo and in vitro.

\section{Materials and Methods}

\subsection{Sample Collection, Isolation, and Identification}

The Koumiss samples were aseptically collected from Inner Mongolia, China. They were inoculated on 2 media: 1. Potato Dextrose Agar (PDA) medium (Potato $300 \mathrm{~g} \mathrm{l}^{-1}$, dextrose $20 \mathrm{~g} \mathrm{l}^{-1}$, agar $15 \mathrm{~g} \mathrm{l}^{-1}$, chloramphenicol $0.1 \mathrm{~g} \mathrm{l}^{-1}$ ) to observe the morphology and quantity of yeasts, and 2 . Gorodkowa medium (peptone $10 \mathrm{gl}^{-1}$, glucose $1 \mathrm{gl}^{-1}, \mathrm{NaCl} \mathrm{gl}^{-1}$, agar $20 \mathrm{~g} \mathrm{l}^{-1}$ ) to observe the structure of ascospores. Plates were incubated at $25^{\circ} \mathrm{C}$ for $72 \mathrm{~h}$. The isolated colonies were purified, and identified initially by biochemical methods including carbohydrate fermentation test, nitrate reduction test, amyloid material test, urease test, and diazo blue B test (DBB) (Guangdong Huankai Microbial Sci. \& Tech, Co. LTD, Guangdong, China) [9]. Then, the yeast isolates were identified to species level by PCR amplification 
of the D1/D2 26S rDNA region using the forward primer (5'-CGCCAGGGTTTTCCCAGTCACGAC-3') and the reverse primer (5'-GAGCGGATAACAATTTCACACAGG-3') [6]. Genomic DNA of the strains were extracted by DNA Extraction Kit Ver.3.0 (TaKaRa, Shiga, Japan) according the manufacturer's instructions. The thermal cycler parameters were: initial denaturation at $94^{\circ} \mathrm{C}, 5 \mathrm{~min} ; 30$ cycles of denaturation at $94^{\circ} \mathrm{C}, 1 \mathrm{~min}$; annealing at $52^{\circ} \mathrm{C}$, $1 \mathrm{~min}$, extension at $72^{\circ} \mathrm{C}, 1 \mathrm{~min}$ and final extension at $72^{\circ} \mathrm{C}, 5 \mathrm{~min}$. The PCR products were resolved on a $1 \%$ agarose gel stained with nucleic acid dye at $110 \mathrm{~V}$ for 30 min, after which the bands were excised from the gel and the DNA was extracted using the TaKaRa Agarose Gel DNA Extraction Kit Ver.4.0 (TaKaRa, Shiga, Japan) following the manufacturer's instructions. DNA strands were directly sequenced by TaKaRa Bio Company (Shanghai, China). BLAST searches of sequences were performed at the NCBI GenBank data library. Finally, the sequence alignments with sequences of the experimental isolates and homologous sequences were performed in GenBank.

\subsection{Screening for Mycocin-producing Yeasts}

The agar diffusion bioassay (Oxford cup method) described by Zhang and others (2013) was used to screen for mycocin-producing yeasts [10]. The indicator bacteria E. coli $\mathrm{O}_{8}$ was a pathogenic E. coli isolated from dairy feces by our laboratory. Aliquot of $100 \mu \mathrm{l}$ of an overnight E. coli $\mathrm{O}_{8}$ suspension was adjusted to $1.5 \times 10^{8}$ colonyforming units (CFU) $\mathrm{ml}^{-1}$ was then inoculated in $20 \mathrm{ml}$ nutrient agar medium (Peptone $10 \mathrm{~g} \mathrm{l}^{-1}$, Beef extract $3 \mathrm{~g} \mathrm{l}^{-1}$, Sodium Chloride $5 \mathrm{~g} \mathrm{l}^{-1}$, Agar $15 \mathrm{~g} \mathrm{l}^{-1}$, Final pH $7.3 \pm 0.2$ ) Petri plates. Three Oxford cups (8 $\mathrm{mm}$ diameter) were placed at equidistance, on each plate. Aliquot of $200 \mu \mathrm{l}$ filtered cell-free supernatant (CFS) of yeast was added to the first Oxford cup. The remaining CFS was adjusted to $\mathrm{pH} 6$ to rule out possible inhibition effects due to organic acids was added to the second Oxford cup. The neutralized CFS was treated with $1 \mathrm{mg} \mathrm{ml}^{-1}$ catalase (3000 $\mathrm{U} \mathrm{mg}^{-1}$ ) (Sigma-Aldrich Co. LLC, MO, USA) at $37^{\circ} \mathrm{C}$ for 30 min to eliminate the possible inhibitory action of $\mathrm{H}_{2} \mathrm{O}_{2}$ was added to the third Oxford cup. They were screened in triplicate.

To confirm whether mycocin had the properties of a protein, the pH-adjusted and $\mathrm{H}_{2} \mathrm{O}_{2}$-eliminated CFS was treated with $1 \mathrm{mg} \mathrm{ml}^{-1}$ pepsin $\left(3000 \mathrm{U} \mathrm{mg}^{-1}\right.$ ) (AMRESCO LLC, OH, USA), trypsin (250 $\mathrm{U} \mathrm{mg}^{-1}$ ) (AMRESCO LLC, $\mathrm{OH}$, USA), proteinase $\mathrm{K}\left(33.5 \mathrm{U} \mathrm{mg}^{-1}\right)$ (Merck KGaA, Darmstadt, Germany), and $\alpha$-chymotrypsin $\left(40 \mathrm{U} \mathrm{mg}^{-1}\right.$ ) (Sigma-Aldrich Co. LLC, MO, USA) at $37^{\circ} \mathrm{C}$ for $2 \mathrm{~h}$ at the optimal $\mathrm{pH}$ of the protease enzymes (pepsin, $\mathrm{pH} 3$; trypsin, $\mathrm{pH} 7$; proteinase $\mathrm{K}, \mathrm{pH} 7.5 ; \alpha$-chymotrypsin, $\mathrm{pH}$ 7.5). If the inhibition zones decreased sharply following treatment with the 4 proteases, the mycocin was confirmed to have the properties of a protein [11].

\subsection{Production of Crude Extracts of Mycocin}

One strain of yeast was chosen for production of crude extracts of mycocin using the method of He [6]. The yeast was inoculated in PDA liquid culture medium and incubated at $25^{\circ} \mathrm{C}$ for $72 \mathrm{~h}$. After centrifuging at $10000 \mathrm{~g}$ for $15 \mathrm{~min}$, the supernatant was filtered through a sterile $0.22 \mu \mathrm{m}$ syringe filter, and divided into 2 parts. One half of the supernatant was adjusted to $\mathrm{pH} 2$ and the second half was adjusted to $\mathrm{pH}$ 8, then added ethyl acetate (Tianjin Yongsheng Chemical Co., LTD, China; the content is 99.5\%) shaken for $4 \mathrm{~h}$. Organic phase and aqueous phase were separated using separating funnel. The organic phase was added $50 \mathrm{ml}$ sterile water and removed ethyl acetate by rotary evaporators, residual antibacterial activity of the organic phase was determined. After centrifuging at $6000 \mathrm{~g}$ for $15 \mathrm{~min}$, residual antibacterial activity of the aqueous phase supernatant was determined. Sterile water was adjusted to $\mathrm{pH} 2$ and $\mathrm{pH} 8$ served as controls. Two phases which had larger inhibition zones were dried for $48 \mathrm{~h}$ by freeze-drying (ModulyoD Freeze Dryer, Thermo Electron Corporation, Thermo Fisher Scientific, Waltham, MA, USA), and were crude extracts of mycocin. The protein concentration of the crude extracts of mycocin were determined using the enhanced BCA Protein Assay Kit (Beyotime Institute of Biotechnology, Jiangsu, China), following the manufacturer's instructions.

\subsection{Temperature Stability of Crude Extracts of Mycocin}

The two phases crude extracts of mycocin described above were treated at $45,60,80,100$, and $115^{\circ} \mathrm{C}$ for 20 min, and at $121^{\circ} \mathrm{C}$ for $15 \mathrm{~min}$. The two phases at $25^{\circ} \mathrm{C}$ served as controls. Residual antibacterial activities of the two phases were determined.

\subsection{Antibacterial Effect of Crude Extracts of Mycocin against $E$. coli in vitro}

The minimal inhibitory concentration (MIC) and the minimum bactericidal concentration (MBC) of the two phases crude extracts of mycocin were determined following the recommendations of the BSAC using broth microdilutions [12]. Briefly, $100 \mu \mathrm{l}$ of an overnight E. coli $\mathrm{O}_{8}$ suspension was adjusted to $10^{6} \mathrm{CFU} \mathrm{m}{ }^{-1}$ and mixed with $100 \mu \mathrm{l}$ of the crude extracts of mycocin dilution in each well. The crude extracts of mycocin were prepared by the double serial dilutions method, and the concentrations of each solution ranged from 0.2 to $0.00625 \mathrm{~g} \mathrm{ml}^{-1}$. The MIC was determined as the lowest concentration that inhibited visible growth after $24 \mathrm{~h}$. The positive and the negative controls were included in each measurement. An aliquot of $10 \mu \mathrm{l}$ from each well was, after $24 \mathrm{~h}$ of incubation, spotted onto nutrient agar medium plates. The MBC was read as the lowest concentration with no growth after $48 \mathrm{~h}$. All MIC/MBC experiments were carried out in triplicate.

\subsection{Antibacterial Effect of Crude Extracts of Mycocin against $E$. coli in vivo}

Sixty Kunming strain mice weighing $18-22$ g were randomly divided into 6 groups of 10 mice each (obtained from Animal Centre of Inner Mongolia University). The animal trial was in accordance with the ethical guidelines. The concentrations of $E$. coli $\mathrm{O}_{8}$ suspension were adjusted to $7.5 \times 10^{10}, 3.75 \times 10^{10}, 1.88 \times 10^{10}, 9.38 \times 10^{9}$, and 4.69 $\times 10^{9} \mathrm{CFU} \mathrm{ml}^{-1}$ by turbidimetry, and were administered intraperitoneally $(0.3 \mathrm{ml})$ to 5 groups of mice to determine $50 \%$ of the minimum lethal dose (MLD) at $72 \mathrm{~h}$. The sixth group served as a control. 
Effects of different doses of two crude extracts of mycocin against $E$. coli $\mathrm{O}_{8}$ were tested using 9 groups of 90 mice. The control group, the negative control group, the positive control group, the high, middle, and low dose groups of one phase crude extracts of mycocin, and the high, middle, and low dose groups of another phase crude extracts of mycocin. Mice were free access to water and food. Mice in the control and negative control groups received $0.2 \mathrm{ml}$ sterile $\mathrm{PBS}$ by gavage, once a day during the 7-d experimental period. Mice in the positive control group received $0.2 \mathrm{ml}$ sterile PBS with $0.13 \mathrm{~g} \mathrm{kg.bw}^{-1}$ Ciprofloxacin (CPFX). Mice in the high, middle, and low dose groups of one phase crude extracts of mycocin received $0.2 \mathrm{ml}$ sterile PBS with 10 000, 5000, $2500 \mathrm{mg}$ kg.bw ${ }^{-1}$ crude extracts, respectively. Except for the control group, mice in other 8 groups were administered intraperitoneally with $0.3 \mathrm{ml} 50 \%$ MLD E. coli $\mathrm{O}_{8}$ suspension at the 4th day. The high, middle, and low dose groups of another phase crude extracts of mycocin were similar with the one phase crude extracts of mycocin groups described above. Survival rates of 9 groups were detected at $72 \mathrm{~h}$ after $E$. coli $\mathrm{O}_{8}$ challenge.

\subsection{Statistical Analysis}

All the experiments on the inhibition zones were carried out as 3 independent experiments and the results are shown as mean \pm S.D. SAS 8.0 was used for statistical analysis. Significant differences between the groups were tested by ANOVA and compared using Duncan's multiple range tests $(P<0.05)$.

\section{Results and Discussion}

\subsection{Identification of the Yeasts Isolated from Koumiss}

The yeast isolates had similar colonial morphologies, they were milky white, round, opaque, moist, and ropy, the diameters of the colonies ranged from 0.2 to $1 \mathrm{~mm}$, they were radial with pseudo or true mycelia, and a budding pattern of asexual reproduction, they had 1 to 4 ascospores with round or irregular shapes, ballistospores were generated in all. The 5 strains were 3 S. cerevisiae, 2 $K$. marxianus as determined by biochemical and PCR identification. The characteristics and species were similar to those reported by Zhang et al [13] and Ni et al [14].
Shuangquan et al [15] reported that Kluyveromyces, Candida, and Saccharomyces spp. played an important role in the fermentation of Koumiss, which is related to the nutrient value and the function of health care. Kluyveromyces and Saccharomyces were also isolated in our research.

\subsection{Screening for Mycocin-producing Yeasts}

Two yeast species showed antibacterial activity against E. coli $\mathrm{O}_{8}$ that is presumed to be attributable to mycocin, which was determined after the neutralization of $\mathrm{pH}$, and the elimination of $\mathrm{H}_{2} \mathrm{O}_{2}$ from the CFS. The mycocins had varying activity following treatment with pepsin, trypsin, proteinase $\mathrm{K}$, and $\alpha$-chymotripsin (Table 1 ). Nevertheless, the lost antibacterial ability following treatment with proteolytic enzymes indicated the proteinaceous nature of the mycocins. Hatoum et al [16] reported that the inhibitive effects of yeasts on some microorganisms have been attributed primarily to 1) a competition for nutrients, 2) $\mathrm{pH}$ changes in the medium resulting in ion exchange or organic acid production, 3) production of ethanol, and 4) secretion of crude extracts of mycocin and the release of crude extracts of mycocin such as "mycocin" [17]. Yang et al [11] reported that organic acids and $\mathrm{H}_{2} \mathrm{O}_{2}$ produced by $\mathrm{LAB}$ had strong antibacterial effects on some microorganisms tested, except in E. coli. We found the organic acids and $\mathrm{H}_{2} \mathrm{O}_{2}$ produced by yeasts exhibited antibacterial effects against $E$. coli which are not consistent with the results of Yang et al [11]. This may be attributed to the fact that the metabolites of the LAB and yeasts and indicator bacteria were different.

Table 1. The inhibition zones of yeasts by 7 treatments $(\mathbf{m m})^{\mathbf{1}}$

\begin{tabular}{|c|c|c|}
\hline Treatment & K. marxianus & S. cerevisiae \\
\hline $\mathrm{CFS}^{2}$ & $16.76 \pm 0.52^{\mathrm{a}}$ & $14.05 \pm 1.61^{\mathrm{a}}$ \\
\hline pH 6.0 CFS & $15.70 \pm 1.27^{\mathrm{ab}}$ & $12.93 \pm 1.12^{\mathrm{a}}$ \\
\hline Catalase & $13.77 \pm 1.31^{\mathrm{bc}}$ & $12.35 \pm 1.35^{\mathrm{a}}$ \\
\hline Pepsin & $12.40 \pm 1.75^{\mathrm{cd}}$ & $10.24 \pm 0.73^{b}$ \\
\hline Trypsin & $11.78 \pm 1.81^{\mathrm{cd}}$ & $9.95 \pm 0.89^{\mathrm{b}}$ \\
\hline Proteinase K & $10.55 \pm 0.61^{\mathrm{de}}$ & $8.58 \pm 1.00^{\mathrm{b}}$ \\
\hline$\alpha$-chymotrypsin & $9.30 \pm 0.10^{\mathrm{e}}$ & - \\
\hline
\end{tabular}

${ }^{2}$ Cell-free supernatant.

Table 2. The inhibition zones of crude extracts of mycocin secreted by $K$. marxianus (mm) ${ }^{1}$

\begin{tabular}{llll}
\hline Crude extracts & $\mathrm{pH} 2$ aqueous phase & $\mathrm{pH} 2$ organic phase & Mixture of $\mathrm{pH} 2$ \\
\hline Diameter & $24.31 \pm 0.81^{\mathrm{a}}$ & $15.22 \pm 0.8^{\mathrm{e}}$ & $20.76 \pm 0.46^{\mathrm{c}}$ \\
\hline Crude extracts & $\mathrm{pH} 8$ aqueous phase & $\mathrm{pH} 8$ organic phase & Mixture of $\mathrm{pH} 8$ \\
\hline Diameter & $22.67 \pm 0.38^{\mathrm{b}}$ & $8.17 \pm 0.08^{\mathrm{g}}$ & $16.86 \pm 0.34^{\mathrm{d}}$ \\
\hline${ }^{1}$ Data represent the mean \pm S.D. in each treatment. Data in each line with different superscript letters indicate the statistical differences determined by \\
ANOVA $(P<0.05)$. “-” was no inhibition zone.
\end{tabular}

\subsection{Production of Crude Extracts of Mycocin}

There were significant differences between each pair of groups in all 8 groups $(P<0.05)$. $\mathrm{pH} 2$ and $\mathrm{pH} 8$ aqueous phases had higher inhibition zones than the others. Hence, they were selected for further study. The mixture of $\mathrm{pH} 2$ and the mixture of $\mathrm{pH} 8$ may be chosen in production to simplify the production steps. The inhibition zone of $\mathrm{pH} 2$ water was $13.74 \pm 0.47 \mathrm{~mm}$, indicating that low $\mathrm{pH}$ had an impact on bacterial growth, but the inhibition zone of $\mathrm{pH}$ 2 aqueous phase was $24.31 \pm 0.81 \mathrm{~mm}$, indicating that the crude extracts of mycocin had the main antibacterial effect against E. coli (Table 2). In the meantime, the protein concentrations of $\mathrm{pH} 2$ and $\mathrm{pH} 8$ aqueous phases crude extracts of mycocin secreted by $K$. marxianus were $749.97 \pm 28.78$ and $741.33 \pm 22.74 \mu \mathrm{g} \mathrm{g} \mathrm{g}^{-1}$, respectively (Table 3). The results of He [6] demonstrated that $\mathrm{pH} 2$ 
and pH 8 organic phases had larger inhibition zones than the aqueous phases, which is not consistent with our results, due to the differences in the source, the species of the yeast, and the experimental conditions.

Table 3. MIC, MBC, and protein concentrations of 2 crude extracts of mycocin secreted by $K$. marxianus

\begin{tabular}{llll}
\hline Items & MIC $\left(\mathrm{g} \mathrm{ml}^{-1}\right)$ & $\mathrm{MBC}\left(\mathrm{g} \mathrm{ml}^{-1}\right)$ & Protein concentrations $\left(\mu \mathrm{g} \mathrm{g}{ }^{-1}\right)$ \\
\hline $\mathrm{pH} 2$ aqueous phase & 0.025 & 0.1 & $749.97 \pm 28.78$ \\
\hline pH 8 aqueous phase & 0.1 & 0.2 & $741.33 \pm 22.74$ \\
\hline
\end{tabular}

decreased when the heat conditions increased (Figure 1).

\subsection{Temperature Stability of Crude Extracts of Mycocin}

The two crude extracts of mycocin secreted by $K$. marxianus were heat-treated from $45^{\circ} \mathrm{C}$ to $121^{\circ} \mathrm{C}$, respectively. The $\mathrm{pH} 2$ aqueous phase was found to be stable at $45^{\circ} \mathrm{C}$ while that of the $\mathrm{pH} 8$ aqueous phase was found to be stable at $45^{\circ} \mathrm{C}$ and $60^{\circ} \mathrm{C}$. The antibacterial activities of the two crude extracts against E. coli $\mathrm{O}_{8}$
In the meantime, the two crude extracts were sensitive to autoclaving at $121^{\circ} \mathrm{C}$ for 15 min displaying either smaller or no inhibition zones compared to the control. Middelbeek [18] reported that the killer toxin of Pichia kluyveri 1002 retained its activity completely upon heating up to $40^{\circ} \mathrm{C}$, but a rapid loss occurred at higher temperatures, which is similar with our results. Therefore, if we use the crude extracts as biopreservatives, they should be not in combination with thermal processing.

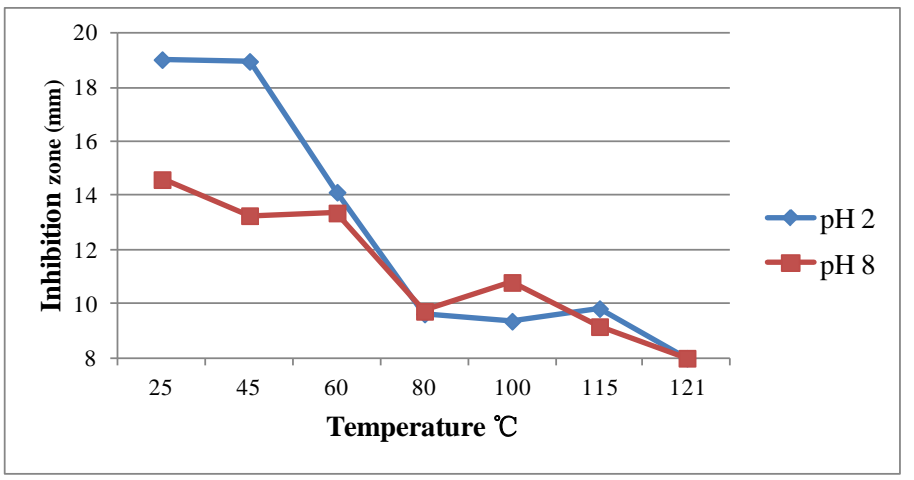

Figure 1. Temperature stability of the 2 crude extracts of mycocin secreted by K. marxianus.

\subsection{Antibacterial Effect of Crude Extracts of Mycocin against $E$. coli in vitro}

The MIC and the MBC of the two crude extracts of mycocin are presented in Table 3. The MIC of $\mathrm{pH} 2$ and $\mathrm{pH} 8$ aqueous phases were 0.025 and $0.1 \mathrm{~g} \mathrm{ml}^{-1}$, and the MBC were 0.1 and $0.2 \mathrm{~g} \mathrm{ml}^{-1}$, respectively, demonstrating that the two crude extracts of mycocin had better antibacterial effect against $E$. coli in vitro.

\subsection{Antibacterial Effect of Crude Extracts of Mycocin against $E$. coli in vivo}

The concentration of $50 \%$ MLD was found to be $4.69 \times 10^{9} \mathrm{CFU} \mathrm{ml}^{-1}$ (Table 4). The antibacterial effect of the different doses of crude extracts of mycocin against $E$. coli $\mathrm{O}_{8}$ are presented in Figure 2. Mice from different experimental groups showed the following survival rates at $72 \mathrm{~h}$ after pathogenic challenge: the control group (100\%), the negative control group (50\%), the positive control group (100\%), the high dose group of $\mathrm{pH} 2$ aqueous phase (80\%), the middle dose group of $\mathrm{pH} 2$ aqueous phase (90\%), the low dose group of $\mathrm{pH} 2$ aqueous phase (100\%), the high dose group of $\mathrm{pH} 8$ aqueous phase (80\%), the middle dose group of $\mathrm{pH} 8$ aqueous phase (90\%), and the low dose group of $\mathrm{pH} 8$ aqueous phase (70\%). The results suggesting that CPFX had a better efficacy against $E$. coli, and the low dose of $\mathrm{pH} 2$ and the middle dose of $\mathrm{pH} 8$ aqueous phases crude extracts showed a better survival rate than other groups. This was consistent with the in vivo trial.

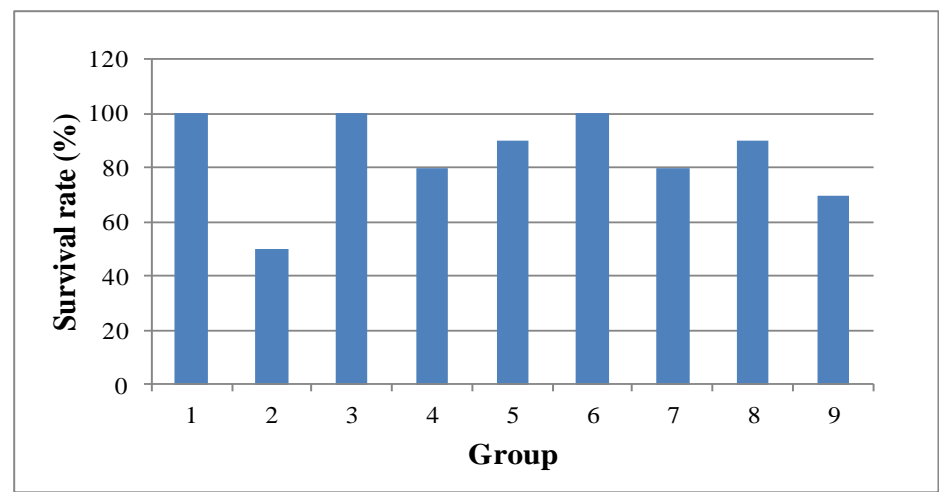

Figure 2. Survival rates of mice received different doses of crude extracts of mycocin at $72 \mathrm{~h}$ after $E$. coli $\mathrm{O}_{8}$ challenge

1-the control group, 2-the negative control group, 3-the positive control group, 4,5,6-the high, middle, low dose group of pH 2 aqueous phase crude extracts of mycocins secreted by K. marxianus, respectively, 7,8,9- the high, middle, low dose group of pH 8 aqueous phase crude extracts of mycocins secreted by K. marxianus, respectively. 
Table 4. The MLD at $72 \mathrm{~h}$ of $E$. coli $\mathrm{O}_{8}$

\begin{tabular}{|c|c|c|c|c|c|}
\hline Concentrations(CFU ml $\left.{ }^{-1}\right)$ & The number of mice & Mortality in $24 \mathrm{~h}$ & Mortality in $48 \mathrm{~h}$ & Mortality in $72 \mathrm{~h}$ & $\operatorname{MLD}(\%)$ \\
\hline $7.50 \times 10^{10}$ & 10 & 10 & 10 & 10 & 100 \\
\hline $3.75 \times 10^{10}$ & 10 & 3 & 10 & 10 & 100 \\
\hline $1.88 \times 10^{10}$ & 10 & 10 & 10 & 10 & 100 \\
\hline $9.38 \times 10^{9}$ & 10 & 4 & 7 & 9 & 90 \\
\hline $4.69 \times 10^{9}$ & 10 & 0 & 0 & 5 & 50 \\
\hline
\end{tabular}

[4] Danova S., Petrov K., Pavlov P., and Petrova, P., "Isolation and characterization of Lactobacillus strains involved in koumiss

\section{Conclusions}

Three Saccharomyces cerevisiae, and two Kluyveromyces marxianus producing mycocin were isolated from traditional Koumiss in Inner Mongolia. $\mathrm{pH} 2$ and $\mathrm{pH} 8$ aqueous phases crude extracts of mycocin secreted by $K$. marxianus were active and stable at temperatures between $25^{\circ} \mathrm{C}$ and $45^{\circ} \mathrm{C}$. They had better antibacterial effect in vitro and in vivo and were shown to be effective in preventing $E$. coli disease in mice, especially the low dose of $\mathrm{pH} 2$ and the middle dose of $\mathrm{pH}$ 8 aqueous phases crude extracts. It may be possible to use crude extracts of mycocin secreted by yeast isolated from Koumiss to inhibit the growth of E. coli.

\section{Acknowledgments}

This work was supported by the National Natural Science Funds, China (31060318), the National Natural Science Funds, China (31160473), the National Natural Science Funds, China (31260590), the "Twelfth Five Year" National Science and the Technology support program (2012BAD12B09-3), the innovation projects of Inner Mongolia graduate education (No. B20141012911).

\section{Conflicts of Interest}

The authors declare no conflicts of interest.

\section{References}

[1] Steinkraus, K.H., Introduction to indigenous fermented foods. In K. H. Steinkraus (Ed.), Handbook of indigenous fermented foods, Marcel Dekker, New York, 1-6. 1996.

[2] Simango, C., "Potential use of traditional fermented foods for weaning in Zimbabwe”. Social Science Medicine, 44(7): 10651068. April. 1997.

[3] 3. Liu, S.N., Han, Y., and Zhou, Z.J., "Lactic acid bacteria in traditional fermented Chinese foods”. Food Research International, 44(3): 643-651. 2011. fermentation”. International Journal of Dairy Technology, 58(2): 100-105. May. 2005.

[5] Kabak, B., and Dobson, A.D.W., "An Introduction to the Traditional Fermented Foods and Beverages of Turkey”. Critical Reviews in Food Science and Nutrition, 51(3): 248-260. 2011.

[6] He, Y. F., "Studies on Isolation, Identification of Microorganisms and Their Antibacterial Factors from Koumiss". Inner Mongolia Agriculture University Doctoral Dissertation (Chinese), 2008.

[7] Viljoen, B., “Yeast ecological interactions. Yeast'yeast, yeast'bacteria, yeast'fungi interactions and yeasts as biocontrol agents,” in Yeasts in Food and Beverages, eds. A. Querol and G. Fleet, Springer, Berlin, 83-110. 2006.

[8] Golubev W.I., Mycocins Killer toxins. In: Kurtzman C.P. and Fell J.W. eds, edn. Elsevier, Amsterdam, The Netherlands, 55-62. 1998.

[9] Barnett J.A., Payne R.W., and Yarrow D., Yeasts: Characteristics and Identification, 3rd edn. Cambridge University Press, Cambridge. 2000

[10] Zhang G.W., Hu M.M., He L., Fu P., Wang L., and Zhou J. "Optimization of microwave-assisted enzymatic extraction of polyphenols from waste peanut shells and evaluation of its antioxidant and antibacterial activities in vitro". Food and Bioproducts Processing, 91(2): 158-168. 2013.

[11] Yang E., Fan L.H., Jiang Y.M., Doucette C., and Fillmore S., "Antimicrobial activity of bacteriocin-producing lactic acid bacteria isolated from cheeses and yogurts". AMB Express, 2(1):48. September. 2012

[12] Skovgaard, S., Larsen, M.H., Nielsen L.N., Skov R.L., Wong C., Westh H., and Ingmer H., "Recently introduced qacA/B genes in Staphylococcus epidermidis do not increase chlorhexidine MIC/MBC”. Journal of Antimicrobial Chemotherapy, 68: 22262233. June. 2013

[13] Zhang, J.R., Yao, X.K., Tan X.H., Liu H., Xiong S.Y., Li J., and Zhang G.Q., "Isolation and Identification of Yeast in Koumiss". Xinjiang Agricultural Sciences (Chinese), 44(2): 206-211. 2007.

[14] Ni, H.J., Bao, Q.H., Sun T.S., Chen X., and Zhang H.P., "Identification and biodiversity of yeasts isolated from Koumiss in Xinjiang of China”, Acta Microbiolgica Sinica (Chinese), 47(4): 578-582. 2007.

[15] Shuangquan., Burentegusi., Yu, B., and Miyamoto, T., "Microflora in traditional starter cultures for fermented milk, hurunge, from Inner Mongolia, China”. Animal Science Journal, 77(2): 235-241. April. 2006.

[16] Hatoum R., Labrie S., and Fliss I., "Antimicrobial and probiotic properties of yeasts: from fundamental to novel applications”. Frontiers in Microbiology, 3:421. December. 2012.

[17] Suzuki, C., Ando, Y., and Machida, S., "Interaction of SMKT, a killer toxin produced by Pichia farinosa, with the yeast cell membranes”. Yeast, 18(16): 1471-1478. December. 2001.

[18] Middelbeek, E.J., Hermans, J.M.H., and Stumm, C., "Production, purification and properties of a Pichia kluyveri killer toxin". Antonie van Leeuwenhoek, 45(3):437-450. 1979. 